This item was submitted to Loughborough's Research Repository by the author.

Items in Figshare are protected by copyright, with all rights reserved, unless otherwise indicated.

\title{
Disaster risk reduction and 'built-in' resilience: towards overarching principles for construction practice
}

PLEASE CITE THE PUBLISHED VERSION

http://dx.doi.org/10.1111/j.1467-7717.2010.01189.x

\section{PUBLISHER}

Wiley-Blackwell (@ Overseas Development Institute / @ The authors)

VERSION

AM (Accepted Manuscript)

LICENCE

CC BY-NC-ND 4.0

\section{REPOSITORY RECORD}

Bosher, Lee S., and Andrew R.J. Dainty. 2019. "Disaster Risk Reduction and 'built-in' Resilience: Towards Overarching Principles for Construction Practice”. figshare. https://hdl.handle.net/2134/7928. 
This item was submitted to Loughborough's Institutional Repository (https://dspace.lboro.ac.uk/) by the author and is made available under the following Creative Commons Licence conditions.

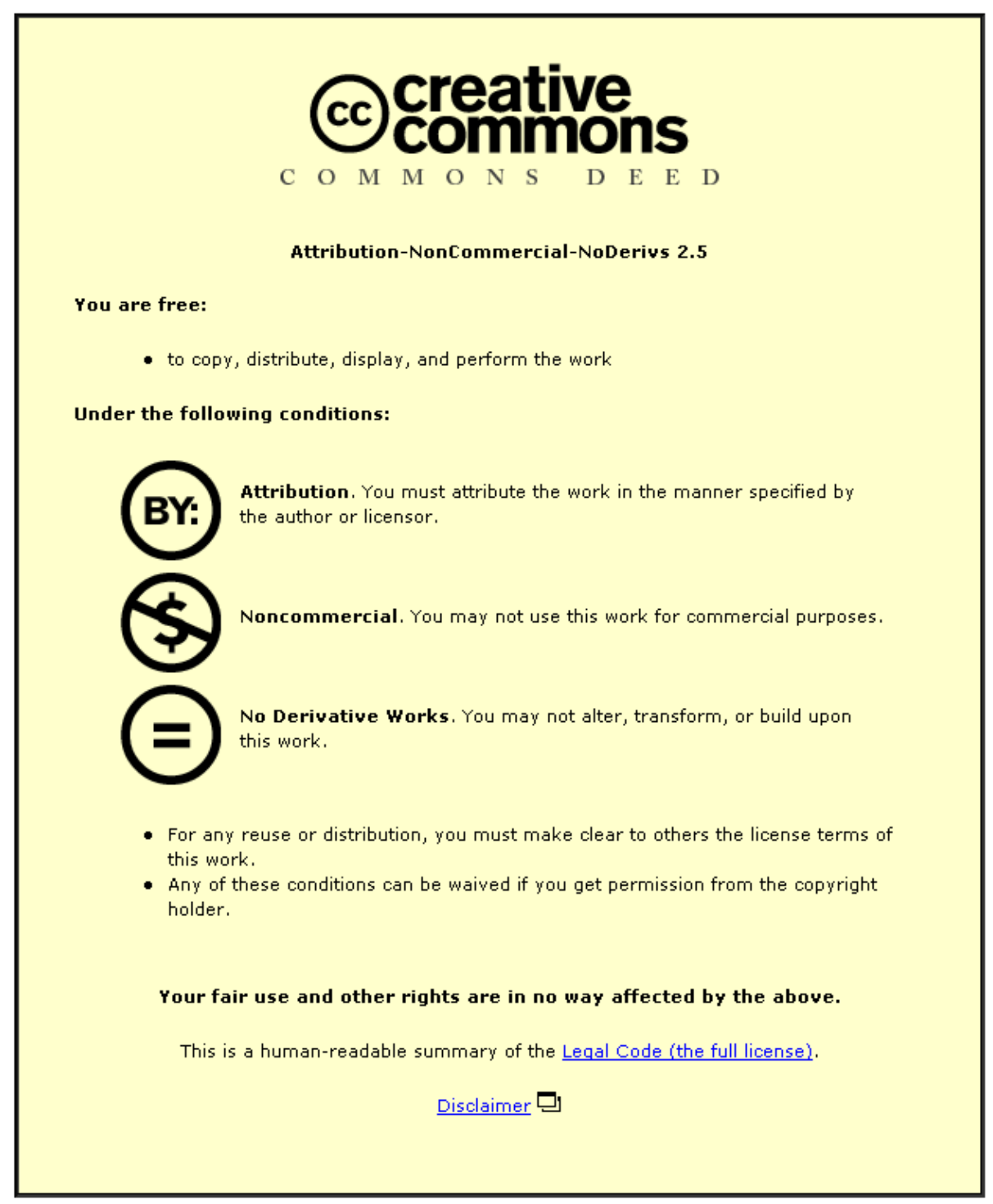

For the full text of this licence, please go to: http://creativecommons.org/licenses/by-nc-nd/2.5/ 


\title{
Disaster risk reduction and 'built-in' resilience: Towards overarching principles for construction practice
}

\author{
Lee Bosher and Andrew Dainty \\ Loughborough University
}

Address for correspondence:

Dr Lee Bosher

Water, Engineering and Development Centre

Department of Civil and Building Engineering

Loughborough University

Loughborough

England LE11 3TU

Tel: 01509222397

E-mail: L.Bosher@Lboro.ac.uk

Please cite this paper as:

Bosher L.S. and Dainty A.R.J., (2011) 'Disaster risk reduction and 'built-in' resilience: Towards overarching principles for construction practice', Disasters: The Journal of

Disaster Studies, Policy and Management, Vol.35, No1, pp. 1-18 


\section{Disaster risk reduction and 'built-in' resilience: Towards overarching principles for construction practice}

Despite recent calls to mainstream Disaster Risk Reduction (DRR) little research has been undertaken on how such resiliency principles can be mainstreamed into planning procedures for major construction projects. The emerging emphasis on DRR has broadened the range of experts and professions whose input must now be garnered, and who must pool their collective knowledge and expertise to resolve complex socio-technical challenges. In this paper the role and position of the construction sector for addressing these concerns is examined. Specifically, it examines the recursive nature of practices within the built environment which arguably deeply ingrain fragmented approaches to the development process. These in turn, render the industry a difficult arena within which to enact structural and cultural change. Based on a synthesis of a wide body of literature and leading authors' contributions to current debates on resiliency, a set of overarching principles are proffered which may help to inform efforts to overcome some of the barriers to creating a more resilient built environment. This is not an attempt to provide a normative framework for design and construction processes, but rather as a general foundation upon which specific initiatives for the creation of a more resilient built environment can be founded. It is argued that they offer a point of departure for configuring methodologies for embedding resilience considerations at both project and institutional levels, although real change would demand challenging some of the conventions which currently underpin construction development.

Keywords: disaster risk reduction, resilience, construction practice, training

\section{Introduction}

It has been argued that designing and constructing a resilient built environment demands an in-depth understanding of the expertise and knowledge of avoiding and mitigating the effects of threats and hazards (Little 2004; Hamelin and Hauke 2005) and that the most influential disciplines that can affect the resilience of the built environment are the design, engineering and construction disciplines (Bosher et al. 2007b). ${ }^{1}$ Amongst other requirements, the United Nations' ‘Hyogo Framework for Action 2005-2015’ (UN/ISDR 2005) calls on governments to mainstream disaster risk reduction considerations, such as designing-in resilience, into planning procedures for major construction projects. In the United Kingdom (UK) these concerns were reinforced in the 'National Security Strategy of the UK' (Cabinet Office 2008a) and a recent Governmental discussion paper focused on the future strategic challenges for Britain (Cabinet Office 2008b). However, to date little research has been undertaken globally on how such resiliency principles can be effectively mainstreamed into large-scale construction projects (Wamsler 2006a). 
In recent years the concept of 'resilience', the capacity of human and physical systems to respond to extreme events, has become increasingly prominent in disaster research. Indeed Tierney and Bruneau (2007) argue that the concept has largely supplanted the concept of 'resistance' with its focus on pre-disaster mitigation. This may reflect the realisation that the changing nature of natural and human-induced threats are such that built assets can never really be futureproofed to be totally resistant. Thus, the contemporary focus has shifted to ensuring the capability of the built environment to both resist and recover rapidly following a disaster event. Despite the theoretical attractiveness of this proposition however, the structure of the construction industry and the nature of the interaction between those who plan, design, construct, operate and maintain the built environment provides a problematic context within which to rehearse integrated disaster risk reduction concepts. In particular, the deeply ingrained structural fragmentation of the industry and its professions arguably act as significant impediments to joining up the various facets of the development process. Ultimately, building-in resilience will demand a paradigm shift in the way that built environment professionals integrate their activities and interact with the communities within which built assets reside.

This paper is based upon the synthesis of a wide range of multi-disciplinary contributions to a recent multi-authored edited book ${ }^{2}$ that has explored the challenges facing the built environment and potential strategies that must now be taken if built-in resilience is to be realised. It seeks both to summarise some of the cross-cutting themes which emerge from a diverse range of literatures and draws upon research from across the world in order to synthesise the issues and challenges that the built environment faces, and to examine the ways in which construction practitioners might adapt their modus operandi to better respond to the threats to the built environment. It is important to recognise that the ideas discussed within this paper would play out very differently in different contexts. Hence, whilst the collective insights of a wide range of disciplines have informed the discussion, it does not seek to proffer any kind of panacea for embedding resilience considerations into the planning, delivery, construction and/or decommissioning of the built environment. Rather, it provides insights into the new directions that researchers and practitioners might take to address these issues in the future. ${ }^{3}$

\section{The susceptibility of the built environment to natural and human-induced hazards}

Everyone interacts with, and is affected by, the built environment; as Hillebrandt (2000) and Han and Ofori (2001) assert the built environment accounts for most of every nation's savings. By the same token however, the impacts of disasters on the built environment can be so profound as to wipe out years of development and investment. In the past two decades alone direct economic losses from disasters totalled US\$629 billion (World Bank 2004). The scale of the threats facing the built environment have clearly escalated in recent years as a result of demographic, economic and socio-political phenomena including increasing global population/urbanisation, climate change and terrorist threat. 
The way in which the built environment has expanded over the past 30 years, with little apparent regard to the evolving climatic conditions (or how humans alter their environment and are thereby positively and negatively affected) has placed much development in a precarious position. It seems clear that an unrelenting desire to build and develop has contributed towards many disasters and/or has exacerbated their effects (Lewis 1999; Wisner et al. 2004). A number of analyses reveal the reciprocal and multifaceted relationship which exists between development and disasters which in some respects determines people's vulnerability (see Wamsler 2008; Wisner et al. 2004). For example, the number of people living at risk of devastating floods worldwide is set to double from one billion in 2004 to two billion by 2050 (United Nations University 2004). Within the United Kingdom (UK), according to the ABI (2004) if house-building rates were to increase to levels recommended in the Barker report (Barker 2004), almost 200,000 homes would need to be built each year on previously developed land for the next 10 years, much of which will be located in the floodplain (see DEFRA 2004). Thus, as Mileti (1999) points out, many emergencies are not unexpected, but stem from the predictable result of interactions between the physical environment, the built environment and the communities that experience them. This principle is well established. Over 30 years ago, O’Keefe, Westgate and Wisner (1976) recognised that the term 'natural disaster' was a misnomer, by questioning how 'natural' so called 'natural disasters' are; highlighting that many disasters are the consequence of the combination of natural hazards and social and human vulnerability. This important point was recently reiterated in a United Nation's report (UN/ISDR 2007) and further highlighted by Bosher (ed. 2008) who suggests that labelling a disaster as 'natural' effectively absolves many stakeholders from blame.

Commentators continue to suggest that the impact of climate change will further increase the prevalence of natural hazards in the future (Munich Re, 2003). A report by the Association of British Insurers (ABI 2005) states that although some advances have been made concerning the protection of the built environment, development pressures, technological changes and climate change will continue to challenge the built environment in the future. Although the scale of the resilience challenge confronting the built environment is not contested within this paper, there is a plethora of evidence to suggest that a differential exists in the threat that natural hazards pose to developed and developing economies. As Morrow (1999) states, the poorest and most socially marginalised are likely to suffer heightened damage from disasters associated with natural hazards and it is now a widely held view that the link between disasters and poverty seems irrefutable (Pelling 2003; Wisner et al. 2004).

What emerges from this discussion is a picture of a built environment under increasing threat from a multiplicity of different hazards, some well established but difficult to mitigate, others more emergent and hence unpredictable. Ofori 
(2008) suggests that the immutable nature of built assets, the inability to accurately test them for resilience to hazards, the legislative and socio-economic requirements of development, requirements for ongoing maintenance, adaptation and redevelopment, and potential appropriation by the end user all render built assets especially vulnerable to a wide range of hazards which will change over time. Arguably a diverse range of hazards are likely to become more significant in future years and so it has become incumbent upon those responsible for planning, designing and constructing the built environment to take account of these threats as a core part of their professional activity. It is the decisions are taken now that will determine the burden that future generations inherit with regards to their resilience to a range of hazards. Therefore, the efficient planning, designing and constructing for resilience now will lessen the need for expensive retrofitted measures in the future.

\section{From Disaster Management to Disaster Risk Management}

Bosher et al. (2007b) argue that the professionals involved in the delivery of the built environment need to become part of the paradigmatic shift from 'disaster management' to 'disaster risk management'. Although the concept of disaster risk management is traceable back to the beginning of the $20^{\text {th }}$ Century (Rollnick 2006), it is gradually becoming institutionalised. This is in part a product of social science research perspectives leading to the realisation that the impact of a natural hazard mostly depends on the capacity of people to absorb the impact and quickly recover from loss or damage (see the work of White 1961, 1964; Dynes and Quarentelli 1977; Maskrey 1989; Burton et al. 1993 and Wisner et al. 2004). The resultant shift of focus has been towards understanding social and economic vulnerability and has contributed to the shift towards ‘bottom-up’, community based and sustainable long-term developmental initiatives related to disaster risk reduction (Bosher et al. 2007a). Disaster risk reduction (DRR) is defined as 'The conceptual framework of elements considered with the possibilities to minimize vulnerabilities and disaster risks throughout a society, to avoid (prevention) or to limit (mitigation and preparedness) the adverse impacts of hazards, within the broad context of sustainable development' (UN/ISDR 2004).

\section{Disaster risk reduction pays}

Benson and Twigg (2007) have published a very useful set of 'Guidance Notes’ for development organisations related to the mainstreaming of disaster risk reduction. The fourteen guidance notes provide short, practical briefs supplementing existing, more general, guidelines on programming, appraisal and evaluation tools. In the report the authors provide some interesting examples that illustrate why hazard-related issues need to be considered in national and sectoral development planning, country programming and in the design of all development projects in hazard-prone countries. The examples include (Benson and Twigg 2007: 6):

- A Vietnam Red Cross mangrove planting programme implemented in eight provinces in Vietnam to provide 
protection to coastal inhabitants from typhoons and storms cost on average US\$ 0.13 million a year over the period 1994 to 2001, but reduced the annual cost of dyke maintenance by US\$ 7.1m. The programme also helped save lives, protect livelihoods and generate livelihood opportunities.

- $\quad$ Spending 1 percent of a structure’s value on vulnerability reduction measures can reduce probable maximum loss from hurricanes by around a third in the Caribbean, according to regional civil engineering experts.

- One dollar spent by FEMA in the USA on hazard mitigation generates an estimated US\$4 on average in future benefits according to a study of FEMA grants (including for retrofitting, structural mitigation projects, public awareness and education, and building codes).

- Only two schools were left standing in Grenada after the passage of Hurricane Ivan (September 2004). Both had been subject to retrofit through a World Bank initiative. One of the schools was used to house displaced persons after the event.

\section{DRR through 'built-in resilience'}

It can be argued that the concept of 'built-in resilience' is a key component of DRR. For instance, a resilient built environment 'should be designed, located, built, operated and maintained in a way that maximises the ability of built assets, associated support systems (physical and institutional) and the people that reside or work within the built assets, to withstand, recover from, and mitigate for, the impacts of extreme natural and human-induced hazards' (Bosher ed. 2008: 13). Such a perspective cross-cuts the multidisciplinary focus of this paper and the appropriateness of disaster risk reduction measures in relation to their compatibility with the context within which they are applied.

The concept of resilience primarily emerged in research concerned with how ecological systems cope with stresses or disturbances caused by external factors (see Errington 1953; Blum 1968), but has more recently been applied to human social systems (Manyena 2006), economic recovery (Rose 2004), engineering (Hollnagel et al. 2006) and urban planning and recovery after calamitous events (Vale and Campanella 2005). Coaffee (2004) argues that there are three key dimensions which differentiate resilience from traditional notions of disaster planning and recovery. Firstly, the emphasis is on hazard mitigation and preparedness rather than post-disaster management. Secondly, there has been a widening of the emergency planning agenda to embrace security challenges in addition to natural hazards and technological 'accidents', this is despite the fact that the latter categories have a far greater collective impact. The third dimension concerns the role of institutional resilience to protect key infrastructural systems. This has necessarily broadened out the range of experts and professions whose input must now be garnered and integrated into the resilience effort. Thus, despite the theoretical attractiveness of disaster risk reduction, its effective delivery in practice is likely to be highly complex and in need of structural support and guidance for those expected to enact it. 


\section{Challenges and impediments to achieving built-in resilience}

As was alluded to above, the scale and expanding nature of the challenges facing the built environment, both 'natural' and human-induced, is a recurring theme in much of the literature. The question is therefore, how the built environment can integrate disaster risk reduction into the processes of designing, locating, building, operating and maintaining (and decommissioning) the built environment. In order to examine this it is firstly important to problematise the construction sector (as the creator of the built environment) as an arena within which to embed disaster risk reduction principles.

Construction is frequently cited as the epitome of a project-based industry. Cherns and Bryant (1984) coined the term ‘Temporary Multiple Organisation' which comprises a complex and temporary array of inter-organisational relationships, governed by project-defined interactions (see Bresnen et al. 2004). Thus, construction projects tend to be planned, designed and constructed by a combination of firms and individuals, many of whom will not have worked together before, and are not likely to work together again. Built environment professionals are involved in an endless process of balancing the objectives of the firm with those of the project. Most new build construction development tends to be large and requiring expensive capital investment (Hillebrandt 1988). Built assets tend to be fixed in location with products are assembled to a unique specification. The fact that each project is different, both in terms of the product and in terms of the people involved, makes it difficult to achieve the degree of repetition and routinisation achieved in other industries (see Bresnen and Marshall 2001). Furthermore, the relatively low skill levels required for many construction operations and the low barriers to entry lead to an informal labour market and an industry that is notoriously difficult to regulate. This exacerbates the widespread corruption from which the industry suffers, which in turn can increase the vulnerability of buildings and structures (see Lewis 2003).

The recursive nature of these influences deeply ingrains practice and renders the industry a difficult arena within which to enact structural and cultural change. The temporary multiple organisation which is formed for each project renders the effective coordination of their efforts around the resilience agenda problematic. Adding expertise in mitigating the effects of disasters to an already cluttered delivery effort further complicates the apportionment of responsibilities for the performance of the built artefact. Professional fragmentation is a hallmark of the industry, with architects, surveyors and engineers usually employed from outside construction firms as independent consultants (Morton 2002). Therefore, propagating resilience through an integrated planning/design/construction/decommissioning effort appears a problematic notion given these structural constraints. 


\section{Discussion: Towards a framework for building-in resilience}

The preceding discussion has revealed the scale of the challenge in developing a more resilient built environment. It has also revealed the need for multiple, mutually reinforcing strategies to be developed concurrently if any real impact on resilience is to emerge. Ofori (2008) breaks down the components of the development process within which resilience must be built-in. These include building regulation and development control, procurement practices, design processes, construction and the operation of the built facility. The plethora of international examples in relation to these areas suggests that frameworks already exist in both developing and developed country contexts. However, there remains an absence of any structured way to ensure that this guidance and promising practice is combined effectively.

There is a clear need to move away from instrumentally rational solutions and to recognise that the way in which resilience should be built-in is largely contingent on context. However, whilst the derivation of a single model for building in resilience is neither feasible nor desirable, broad principles can be drawn as a point of departure for the development of context-sensitive resilience frameworks in the future. The seven guiding principles are based largely upon the work of many contributions to an edited volume (see Bosher ed. 2008; the contributing authors are acknowledged at the end of this paper); the guiding principles are:

1. Adopt a holistic perspective;

2. Develop and appropriately apply resilient technologies;

3. Engage a wide range of stakeholders (including local communities) in resilience efforts;

4. Utilise existing guidance and frameworks when appropriate;

5. Exploit opportunities to build-in resiliency measures post-disaster;

6. Integrate built environment and emergency management professionals into the DRM process, and;

7. Mainstream resilience into the built environment curricula.

It is anticipated that adoption of these seven guiding principles could support efforts by 'agencies' that should be involved with improving national, regional and local resilience.

\section{Adopt a holistic perspective}

Alexander (2008) explains the factors impeding the application of disaster risk reduction practices include, the failure to apply knowledge, the failure to agree common standards, the need for professionalisation, problems with knowledge transfer and the apparent focus on technological over social issues. Whilst not insurmountable, it is arguably the systemic and mutually reinforcing nature of these barriers which render the achievement of built-in reliance so problematic. Breaking down individual dimensions will arguably do little to overcome the ingrained problems in 
adopting a disaster risk management perspective, particularly in hazardous areas. Rather, a more holistic perspective is required within which the systemic impacts of such factors are considered.

A second issue concerns the need to view resilience and response as interrelated and mutually intertwined concepts. Response activities that do not take due regard of, or learn from, reconstruction, hazard mitigation and preparedness requirements are likely to overlook key opportunities to attain not only physical resilience, but also social and economic resilience. Inappropriate responses to post-disaster situations can take a number of forms, such as:

1. Responses that do not reach out to the most affected people but are targeted towards favoured communities such as socio-political elites. It is in these situations that some sectors of society, such as the elderly, the poor, and marginalised communities (based for example on religious, political, or caste related grounds) may not only be excluded from receiving post-disaster relief aid but also assistance towards recovery and reconstruction activities (Wisner et al. 2004; Bosher 2007). It is therefore important to appreciate that when already existing socioeconomic vulnerabilities are not being reduced, a key consequence is that social resilience is unlikely to be increased.

2. Post-disaster responses and reconstruction efforts that are overly influenced by a political and economic will to 'reconstruct quickly' (with the misguided belief that this will help society to 'bounce-back') are not conducive to the attainment of physical or social resilience. As Menoni (2001:105) notes, 'Market forces put pressures to reconstruct as quickly as possible transportation networks to long distances and commercial and office buildings, hampering efforts to implement lessons learnt from the disaster in the attempt to reduce ... vulnerability'. Therefore, hazard mitigation and preparedness activities need to be intertwined with response and reconstruction activities; it is through this holistic approach that physical and social resilience is more likely to be attained.

Therefore, by viewing resilience and response as interrelated and mutually compatible concepts it should be possible to embed hazard mitigation and preparedness considerations into post-disaster response and reconstruction; to seize the opportunity to learn and implement the lessons learnt. Although this might sound like a straightforward suggestion, it presents many theoretical and practical challenges. The task of reconstruction after a major event requires coordinated efforts of all stakeholders for effective and efficient recovery of the affected community. Without developed frameworks for legislation and procurement, reconstruction and new development will be carried out on an ad-hoc basis with little regard for the needs of society. 


\section{Develop and appropriately apply resilient technologies}

Developing resilient technologies is, of course, also of paramount importance to mitigating threats to the built environment. However, a recurring theme concerns the need to develop resilient technologies which are sensitive to the socio-economic environment within which they are to be used. Petal et al. (2008) critique the top-down, technologically-driven reconstruction projects that typify many post-disaster reconstruction efforts. These typically engage outside engineers and builders and use technologies which supplant both local knowledge and local labour. There are several implications of applying inappropriate technologies and processes in this context, particularly in terms of the likely disengagement of local stakeholders with the development process. As Petal et al. state "People who have homes built for them —without consultation, without information and without choice-will naturally adopt a fatalistic view of the product" (2008: 192).

A good example of appropriate construction is provided by Jigyasu (2002) who explains how the traditional seismic resistant construction systems found in Gujarat have withstood earthquakes (for instance, by virtue of their floor joists that extend through rubble stonewalls to support balconies). Such traditional structures that have evolved over many centuries are also sensitive to the locally available resources, the environment in which they are constructed and the spatial requirements of those who inhabit them. Arguably, these considerations are as pertinent for developed as well as developing country contexts.

\section{Engage communities in resilience efforts}

The nature of threats to the built environment are such that there will always be unintended consequences associated with attempts to improve resilience. It has to be recognised therefore, that future threats cannot be predicted any more accurately than the future socio-economic circumstances of the countries within which they will occur because vulnerability cannot be separated from the social and cultural conditions under which it exists (see Comenetz and Caviedes 2002; Ewing et al. 2005; Wisner et al. 2004).

The challenge for researchers and practitioners is to design flexible and responsive solutions which can adapt to the changing physical threats that they face and the evolving institutional context within which they are embedded. It is here where traditional knowledge is key to ensuring the long-term resilience of new built assets. There is a need to advocate a variety of methods to create a bespoke approach towards meeting local community expectations, supported through meaningful consultation methods. This can enable the local socio-economic status of the population at risk to be considered. Engaging the user community is of course key in gaining acceptance for resilient measures, especially when these impact on the environment or utility of the built asset in any way. 
Community based disaster risk reduction, as espoused by Petal et al. (2008), appears to offer a potential solution for overcoming the failures of legislative 'sticks' to generate more resilient solutions. As they state "This approach shifts away from punishment as a primary motivator and instead points toward a community-based imperative that emphasises users and builders who are educated sufficiently to take the lead in voluntary compliance and in developing a critical mass providing leadership from the grass roots up" (2008: 195). The framework presented suggests that shared information, local ownership, positive relationships founded on dialogue, capacity building and robust evaluation can provide a framework for embedding this type of community involvement. ${ }^{4}$

\section{Utilise existing guidance and frameworks when appropriate}

The challenge of disaster risk reduction is largely a matter of how to apply existing knowledge (investment and adaptation and of reducing the 'implementation shortfall') rather than generating new knowledge per se. The research challenge, therefore, is grounded in the process of technology transfer and diffusion. Adopting selected elements of existing guidance for building in resilience is a sensible starting point for determining methods for embedding the principles of disaster risk reduction within existing professional activities. Many of these frameworks are sufficiently flexible and reconfigurable to enable the user to appropriate them for their own requirements and contexts in any case. Others require some development in order that they align with the context within which they are to be applied.

Some interesting frameworks have been developed which may offer appropriate starting points for achieving the principles set out above. For example in the UK, the Civil Contingencies Act (CCA) 2004 (Cabinet Office 2004) was created to outline new duties for 'responder organisations' and provide a framework within which emergency response duties were to be implemented. The essence of the Act is one of multi-disciplinary and multi-hazard planning; engaging a broad range of structural and non-structural measures to mitigate potential hazards and reflected a paradigm shift in the management of disasters in the UK. The principles enshrined within are to enable continuity of service before, during and after critical incidents by ensuring the structural and collaborative conditions are in place to respond effectively. The CCA encourages bilateral and regional (but not necessarily international) cooperation to be developed outside the typical civil contingencies framework. From a built environment professional's point of view this is important because it is inconceivable that CCA responders would not call upon engineers (for instance) in some shape or form when developing emergency plans. The six step planning process seems to offer a useful framework for integrating the wide range of disciplinary expertise required to assist in the attainment of a more resilient built environment. 
From a slightly different perspective, Wamsler's model (2008: 341) provides a point of departure for those seeking to better integrate disaster risk management into construction planning practices. Based on seven complementary strategies, it could help to translate disaster risk reduction strategies into tangible working practices. In a similar vein, the 'Operational Framework for Integrating Risk Reduction' by the Benfield Hazard Research Centre (Wamsler 2006b) is a framework and tool that complies with all seven of the guiding principles that are discussed in this paper, and more importantly is already in use by different stakeholders. These examples provide good starting points for those wishing to integrate disaster risk reduction into the planning and construction processes.

\section{Exploit opportunities to build-in resiliency measures post-disaster}

Whilst the focus of this paper is not on post-disaster reconstruction, there appears to be an acceptance of the need for more resilient measures post disaster. Glavovic (2008) has acknowledged that in the past, disaster events have been dealt with in a response-driven manner with a compelling focus on saving lives, providing emergency relief and marshalling resources for restoration and reconstruction. More recently, it has been recognised that these vital measures need to be complemented by a more holistic, proactive and developmental approach that seeks to address pre-event vulnerabilities (Oliver-Smith and Hoffman 2002; Wisner et al., 2004). For instance, Soetanto et al. (2008) have revealed that some construction professionals in the UK are appreciative of the need to incorporate resilient measures into the repair of flood damaged property. Thus, those with responsibility for post-disaster reconstruction and retrofitting post event are often amenable to taking on board resilient technologies given that they have witnessed the effects of the initial threat. This is supported by Le Masurier et al. (2006), who contend that addressing the contractual and legislative approaches to post-disaster reconstruction prior to any event will help to build in resilience for a community by assisting post-event recovery and reconstruction efforts. However, Le Masurier et al. (ibid) also note that existing regulatory provisions may constrain reconstruction efforts by causing difficulties in apportioning multi-agency responsibilities, co-ordination and resource allocation. Consequently, it has been proposed that a National Policy Framework for Post-Disaster Reconstruction in New Zealand is required (see Rotimi et al. 2008).

In addition, the ‘Transitional settlement and reconstruction principles’ (UN 2008) have recently been designed to assist all stakeholders responding to rapid-onset disasters, especially those responsible for planning and coordination in governments and humanitarian and developmental organisations. Such frameworks should also be considered for all disaster affected nations as it is these types of proactive measures that can be key to building more resilient communities and the critical lifeline services that society so often relies upon. 
It is also important to acknowledge that post-disaster reconstruction in developing countries has experienced a shift from donor driven approaches (aid agencies building houses for people) to owner driven (people being given cash to build their own houses). This trend effectively means that rather than agencies and their contractors needing to incorporate resilient technologies and designs it has become important to ensure that people who are given grants to reconstruct are also given support to incorporate resilient features and that regulations are appropriate and enforced (see Barenstein 2006).

\section{Integrate built environment and emergency management professionals into the DRM process}

There is undoubtedly an urgent need for the construction industry to adopt a disaster risk management (DRM) perspective. Professional institutions and trade associations should enhance the awareness of their members of the need to assess the risks of disasters in order that they take the necessary precautions at all stages of the planning, design and construction processes. However, the difficulties of trying to do so in an environment with typically fragmented relationships between the various actors renders this a problematic notion (see Trim 2004; Lorch 2005; Bosher et al. 2007b). Achieving built-in resilience demands that traditional demarcations in roles and responsibilities are reconstituted in order to propagate the free-flow of knowledge between the stakeholders of the built environment. Glass (2008) states that the role of the architect is particularly interesting in this regard because of their ability to profoundly influence the design process through their interpretation of a brief and specification and configuration of materials. Glass (ibid) views the role as comprising two concurrent but fundamentally different roles, that of an 'information manager' and that of a 'creative individual'. This leads to a requirement to blend subjectivity and objectivity throughout the design process which places architects in an excellent position for coalescing other influential participants around them in support of the resilience effort.

The need for integration extends beyond the need to join-up built environment professionals’ activities. Glass (2008) also argues that there is a disconnect between emergency managers and the construction industry. This view is congruent with that of Lorch (2005), who believes that some of the non-technological problems of emergency planning are a demonstration of the disciplinary boundaries within the scientific community and between the scientific community and the policy community. Policy makers, practitioners and the academic community must develop a collective approach for embedding hazard risk reduction and emergency management into the mainstream riskmanagement process. 


\section{Mainstream resilience into the built environment curricula}

Some advances have been made in recent years to incorporate the roles of construction professionals into debates regarding topics such as climate change and sustainability. However, the integration of construction professions with processes associated with disaster risk management (DRM) has largely been ignored (Spence and Kelman 2004). In the longer term there has to be a real and sustained commitment to mainstreaming the need for a resilient built environment into the education programmes of those who are charged with planning, designing, constructing and operating/maintaining it (Bosher et al. 2007a). Ofori (2008) suggests the redesign of the curricula of professional programmes to cover the relevant aspects of disaster risk management and disaster risk reduction. This view is supported by Lorch (2005) who sees higher education and training playing a major part in the integration of sustainable development and hazard, vulnerability and risk reduction principles into the domain of built environment students. This is more problematic than it may first appear given the need for professionals to respect the local context within which disaster risk reduction takes place. This requires a change in attitudes towards construction development as well as knowledge of how to design and construct for hazard mitigation. Glass (2008) suggests that rather than mainstream resilience into architectural profession, there well may be a role for architectural practices to decide to specialise in resilient building design. She suggests that this is more plausible given there is simply too much to learn to treat resilience as just another facet of regular building design. This view is echoed by Petal et al. (2008), who suggests that championing old and new community-based construction approaches for disaster risk reduction will require acculturating a generation of technical specialists and practitioners. This will require higher education techniques and on-the-job training in order to equip those responsible for engaging local communities with the skills necessary for buyin and involvement in resilient solutions. The 'Tools for Mainstreaming Disaster Risk Reduction' (particularly Guidance note 12, 'Construction Design, Building Standards and Site Selection’ $)^{5}$ that have been developed by Benson and Twigg (2007) provide useful foundations upon which some of this training (professional, 'on the job' and community based education) can be achieved.

However, Jigyasu (2008) states that it is important to avoid the too common categorisation of traditional and 'Scientific Knowledge' into mutually exclusive domains. This concern is based upon the work of Flavier et al. (1995) who have stated that traditional information systems are dynamic and continually influenced by the internal creativity and experimentation as well as the contact with external systems. This continuous process of experimentation, innovation and adaptation enables traditional knowledge to blend with science and technology as well. Therefore Jigyasu (2008) suggests that attempts should be made to reconcile the two; science can enable traditional knowledge systems to be easily understood by the professionals, and traditional knowledge enables scientific concepts to be translated into modes of communication that are locally understood. The theoretical attractiveness of this proposition is obvious, but its 
practical realisation requires both open-mindedness on the part of built environment professionals and local communities to embrace traditional/contemporary methods, and the safeguarding of the traditional skills and knowledge but informed by scientific understanding of future hazards. However, overcoming these challenges is necessary to safeguard and diffuse the knowledge of traditional techniques which have demonstrably led to hazard resistant buildings in the past. Adapting and reapplying this knowledge will ensure that hazard mitigation techniques can evolve in a way which accords with the changing nature of threats as they will be informed by the involvement of those with knowledge of the local context.

\section{Conclusions}

During the last few decades a range of high profile disasters have stimulated an escalation in theoretical developments in relation to the way in which disasters can be avoided and managed. A paradigmatic shift has led to a focus on disaster preparedness, hazard mitigation and vulnerability reduction rather than the often reactive focus on disaster management and relief. It is therefore not surprising that the discourse of resilience now resonates throughout many international bodies as well as national governments and the disciplines involved with the mitigation of natural and human induced hazards. Despite this new emphasis, the construction industry is arguably poorly positioned for embracing the tenets of DRR. Its structural fragmentation sustained by ingrained practices which have emerged from the temporal nature of projects arguably present a problematic arena within which to enact the joined-up thinking necessary to mainstream resiliency into the built environment.

This paper has summarised some of the key themes emerging from a diverse body of literature which has considered various facets of the resiliency agenda. By drawing upon multiple insights and contexts, a range of principles have been identified which have the potential to address or circumvent the social, structural, economic and process-related barriers to achieving built-in resilience. The perspectives that have contributed towards these guiding principles highlight the varying levels of input that are required; embracing the formally and informally trained construction professionals and artisans as well as the 'client' and the 'community', the governmental policy maker and the non-governmental organisation; in fact a significant range of decision makers involved in the delivery of the built environment. The range of issues covered not only demonstrate the trans-disciplinary nature of the issues but also illustrates that non-structural as well as structural adaptations need to be considered to reduce the threat, and impact, of disasters and that lessons can be learnt from a range of disciplines and socio-cultural contexts. Ideally these principles should be considered in an integrated way as they should be mutually reinforcing (i.e. addressing one will inevitably have an influence on the how the other principles are addressed). However for this to be achieved governments, the commercial sector and civil 
society will urgently need to prioritise disaster risk reduction as a critical development challenge and make concerted efforts to develop related policies, capabilities and legislative and institutional arrangements (Benson and Twigg 2007).

In attempting to join-up and synthesise the various insights reviewed within this paper, it has been necessary to problematise the notion of achieving built-in resilience. Two factors stand out in this regard. Firstly, the complexity and interrelatedness of the array of continually evolving threats facing the built environment and its users present a continually shifting set of resilience parameters against which built assets should be evaluated. This suggests a need for fresh criteria for establishing the appropriateness of construction development which embraces the resiliency agenda. Secondly, the institutional resistance to change which pervades the construction industry stands as a considerable barrier to enacting the kinds of generic approaches advocated within this paper. Thus, although these principles offer a point of departure when configuring methodologies for embedding resilience considerations in the future, and a framework for supporting the required shift towards more proactive disaster risk reduction, the real challenge is in developing the specific approaches necessary to account for individual contexts and situations. These may challenge some of the conventions which currently underpin construction development.

\section{Acknowledgements}

The authors wish to acknowledge the important contributions of those that contributed towards the edited book from which these seven guiding principles have emerged, namely David Alexander, Guillaume Chantry, Jon Coaffee, Amod Dixit, Andrew Fox, Jacqueline Glass, Rebakah Green, Rohit Jigyasu, Ilan Kelman, Jessica Lamond, Jason Le Masurier, James Lewis, Simon McCarthy, John Norton, George Ofori, Stefano Pampanin, Edmund Penning-Rowsell, Marla Petal, David Proverbs, James Rotimi, Victor Samwinga, Rajib Shaw, Robby Soetanto, Sylvia Tunstall, Christine Wamsler, Suzanne Wilkinson and Kelvin Zuo.

\section{References}

ABI, (2005) Safe as Houses? Flood risk and sustainable communities, London, Association of British Insurers, London Alexander D., (2008) 'Mainstreaming disaster risk management’: in Bosher L.S., (ed.), (2008): 20-36

Barenstein, J.D. (2006). Housing reconstruction in post-earthquake Gujarat: A comparative analysis, Network Paper No. 54, Overseas Development Institute/Humanitarian Practice Network, London (www.odihpn.org).

Barker K., (2004) Review of Housing Supply: Delivering stability: securing our future housing needs, Office of the Deputy Prime Minister, HMSO, London 
Benson C. and Twigg J., (2007) Tools for Mainstreaming Disaster Risk Reduction: Guidance Notes for Development Organisations, Geneva: International Federation of Red Cross and Red Crescent Societies/The ProVention Consortium

Blum J.L., (1968) 'Salt Marsh Spartinas and Associated Algae’, Ecological Monographs, 38(3): 199-221

Bosher L.S., (2007) Social and Institutional Elements of Disaster Vulnerability: The Case of South India, Academica Press, Bethesda, USA

Bosher L.S., (ed.), (2008) Hazards and the Built Environment: Attaining Built-in Resilience, Taylor and Francis, London

Bosher L.S., Carrillo P.M., Dainty A.R.J., Glass J., and Price A.D.F., (2007a) 'Realising a resilient and sustainable built environment: Towards a strategic agenda for the United Kingdom’, Disasters, 31(3): 236-255

Bosher L.S., Dainty A.R.J., Carrillo P.M., Glass J., and Price A.D.F., (2007b) ‘Integrating disaster risk management into construction: A UK perspective', Building Research \& Information, 35(2): 163-177

Bresnen M. and Marshall N., (2001) Understanding the diffusion and application of new management ideas in construction, Engineering, Construction and Architectural Management, 8(5/6): 335-345

Bresnen M.J., Goussevskaia A. and Swan J., (2004) Embedding New Management Knowledge in Project-Based Organizations. Organization Studies, 25(9): 1535-1555

Burton I., Kates R.W., and White G., (1993) The Environment as Hazard: Second Edition, Guilford Press, London

Cabinet Office, (2008a) National Security Strategy of the United Kingdom: Security in an interdependent world, Cabinet Office, London

Cabinet Office, (2008b) Realising Britain’s Potential: Future Strategic Challenges for Britain, Cabinet Office, London

Cabinet Office, (2004) The Civil Contingencies Act 2004 (Contingency Planning) Regulations, Civil Contingencies Secretariat, Cabinet Office, London

Cherns A. B. and Bryant D .T., (1984) Studying the client's role in construction, Construction Management and Economics, 2: 177-84

Coaffee J., (2004) 'Rings of Steel, Rings of Concrete and Rings of Confidence: Designing out Terrorism in Central London Pre and Post 9/11', International Journal of Urban and Regional Research, 28(1): 201-11

Comenetz J. and Caviedes C., (2002) 'Climate variability, political crises, and historical population displacements in Ethiopia’, Environmental Hazards, 4(4): 113-127

Dainty A.R.J. and Bosher L.S., (2008) ‘Integrating resilience into construction practice’ in: Bosher L.S., (ed.), (2008): pp. 357-372

DEFRA, (2004) Study into the environmental impacts of increasing the supply of housing in the UK, DEFRA Statistics, Department for Environment, Food and Rural Affairs, London 
Dynes R. and Quarantelli E. L., (1977) Organisational Communications and Decision-making in Crises, Report, Series 17, Disaster Research Centre, Ohio State University, Columbus

Errington P.L., (1953) ‘Reviewed Work(s): Natural Communities by Lee R. Dice’. Science, New Series, 117(3028): p.43

Ewing, B.T., Kruse, J.B. and Thompson, M.A., (2005) 'Empirical examination of the Corpus Christi unemployment rate and Hurricane Bret', Natural Hazards Review, 6(4): 191-6

Flavier J.M., de Jesus A. and Navarro C., (1995), 'The regional program for the promotion of indigenous knowledge in Asia’: in Warren D.M., Slikkerveer L.J. and Brokensha D., (eds), (1995) The cultural dimension of development: Indigenous knowledge systems, Intermediate Technology Publications, London, pp. 479-487

Geis D.E., (2002), 'The Shanghai Principles for Creating Safer Cities and Societies Through Sustainable Urban Development', 5th International Conference of Local Authorities for Confronting Disasters \& Emergencies, 15-27 October, Shanghai, http://training.fema.gov/emiweb/downloads/THESHANGHAIPRINCIPLES.doc

Glass J., (2008) 'Facing the future by designing in resilience: An architectural perspective’: in Bosher L.S., (ed.), (2008): 172-188

Glavovic B.C., (2008) ‘Katrina recovery experiences: Imperatives for building sustainable, hazard-resilient communities', Proceedings of the Information and Research for Reconstruction (i-Rec) Fourth International Conference on 'Post-disaster reconstruction: Building resilience - achieving effective post-disaster reconstruction, 30th April - 2nd May, University of Canterbury, Christchurch, New Zealand

Hamelin J-P. and Hauke B., (2005) Focus areas: Quality of Life - Towards a Sustainable Built Environment, European Construction Technology Platform, Paris

Han S.S. and Ofori G., (2001) ‘Construction industry in China’s regional economy’, Construction Management and Economics, 19(2): 189-205

Hillebrandt P.M., (2000) Economic Theory and the Construction Industry, third edition, Macmillan, Basingstoke Hillebrandt P.M., (1988) Analysis of the British Construction Industry, Macmillan, London

Hollnagel E. Woods D.D. and Leveson N., (eds.) (2006) Resilience Engineering: Concepts and Precepts, Ashgate Publishing, Aldershot

Jigyasu R., (2008) ‘Structural adaptation in South Asia: Learning lessons from tradition’ in: Bosher L.S. (ed.), (2008): pp.74-95

Jigyasu R., (2002) ‘Reducing disaster vulnerability through local knowledge and capacity’, Dr Eng thesis, Norwegian University of Science and Technology, Trondheim 
Le Masurier J., Rotimi J.O.B. and Wilkinson S., (2006) ‘A comparison between routine construction and post-disaster reconstruction with case studies from New Zealand', in Boyd D., (ed.) Proceedings of the 22nd Annual ARCOM Conference, 4-6 September, Birmingham, UK

Lewis J., (2003) 'Housing construction in earthquake-prone places: perspectives, priorities and projections for development', Australian Journal of Emergency Management, 18(2): 35-44

Lewis J., (1999) Development in Disaster-prone Places: Studies of Vulnerability, Intermediate Technology Publications, London

Little R., (2004) ‘Holistic strategy for urban security’, Journal of Infrastructure Systems, 10(2): 52-9

Lorch R., (2005) What lessons must be learned from the tsunami?, Building Research and Information, 33(3): 209-11

Maskrey A., (1989) Disaster Mitigation: A Community Based Approach, Oxfam, Oxford

Manyena S.B., (2006) 'The concept of resilience revisited', Disasters, 30(4): 433-450

Menoni S., (2001) 'Chains of damages and failures in a metropolitan environment: some observations on the Kobe earthquake in 1995', Journal of Hazardous Materials, 86(1-3):101-19

Mileti D.M., (1999) Disasters by Design: A Reassessment of Natural Hazards in the United States, Joseph Henry Press, Washington, DC

Morrow B.H., (1999) ‘Identifying and mapping community vulnerability’, Disasters, 23(1): 1-18

Morton R., (2002) Construction UK: Introduction to the Industry, Blackwell Publishing, Oxford

Munich Re, (2003) Topics: Annual Review: Natural Catastrophes, Munich Re Group, Munich

Ofori G., (2008) ‘Construction in developing nations: Towards increased resilience to disasters’, in: Bosher L.S., (ed.), (2008): pp.39-60

O’Keefe P., Westgate K. and Wisner B., (1976) ‘Taking the naturalness out of natural disasters’, Nature, 260: 566-567

Oliver-Smith A. and Hoffman S.M., (2002) Why Anthropologists Should Study Disasters, in Catastrophe and Culture: The Anthropology of Disaster, School of American Research Press, Santa Fe

Pelling M., (2003) The Vulnerability of Cities: Natural Disasters and Social Resilience, Earthscan, London

Petal M., Green R., Kelman I., Shaw R. and Dixit A., (2008) 'Community-based Construction for Disaster Risk Reduction’: in Bosher L.S., (ed.), (2008): 191-217

Rollnick R., (2006) 'The aftermath of natural disasters and conflict’, Habitat Debate, 12(4): 4-5

Rose A., (2004) 'Defining and Measuring Economic Resilience to Disasters,' Disaster Prevention and Management, 13(4): 307-14

Rotimi J.O., Wilkinson S. and Myburgh D., (2008) ‘Towards a national policy framework for post-disaster reconstruction in New Zealand', Proceedings of the Information and Research for Reconstruction (i-Rec) Fourth 
International Conference on 'Post-disaster reconstruction: Building resilience - achieving effective post-disaster reconstruction, 30th April - 2nd May, University of Canterbury, Christchurch, New Zealand

Smart Communities Network, (n.d.), 'The Wingspread Principles: A Community Vision for Sustainability: DisasterPreparedness - Building for a Sustainable Future’, http://www.smartcommunities.ncat.org/wingspread2/wingprin.shtml (accessed $1^{\text {st }}$ May 2008)

Soetanto R., Proverbs D., Lamond J. and Samwinga V., (2008) 'Residential properties in England and Wales: An evaluation of repair strategies towards attaining flood resilience': in Bosher L.S., (ed.), (2008): 124-149

Spence R. and Kelman I., (2004) ‘Editorial: Managing the risks from natural hazards’, Building Research \& Information, 32(5). pp. 364-67

Tierney K. and Bruneau M., (2007) ‘Conceptualizing and Measuring Resistance: A Key to Disaster Loss Reduction’, TR News 250, May - June 2007, pp 14-17

Trim P., (2004) 'An integrated approach to disaster management and planning', Disaster Prevention and Management, 13(3): 218-25

UN, (2008), Transitional settlement and reconstruction after natural disasters: Field Edition, Office for the Coordination of Humanitarian Affairs (OCHA), United Nations, Geneva

UN/ISDR, (2007) Disaster Risk Reduction: 2007 Global Review, Consultation Edition, United Nations International Strategy for Disaster Reduction, Geneva

UN/ISDR, (2005) Hyogo Framework for Action 2005-2015: Building the Resilience of Nations and Communities to Disasters, United Nations International Strategy for Disaster Reduction, Geneva

UN/ISDR, (2004) Living with Risk: A Global Review of Disaster Reduction Initiatives, United Nations International Strategy for Disaster Reduction, Geneva

United Nations University, (2004) Two billion people vulnerable to floods by 2050. News Release, 13 June 2004. Online. Available: HTTP: http://www.unu.edu/news/ehs/floods.doc (Accessed: 17 September 2007)

Vale L.J. and Campanella T.J., (eds), (2005) The Resilient City: How Modern Cities Recover from Disaster, Oxford University Press, Oxford

Wamsler C., (2008) 'Planning ahead: adapting settlements before disasters strike’, in Bosher L.S., (ed.), (2008): pp.317-354

Wamsler C., (2006a) 'Mainstreaming risk reduction in urban planning and housing: a challenge for international aid organisations', Disasters, 30(2):151-177

Wamsler C., (2006b) Operational Framework for Integrating Risk Reduction for Aid Organisations Working in Human Settlement Development, Housing and Development and Management Working Paper, No.14, Benfield Hazard Research Centre/Lund University, 
http://www.sheltercentre.org/sites/default/files/BHRC_IntegratingRR4AidOrgsInHumanSettlements.pdf (accessed

$4^{\text {th }}$ October 2007)

White G. F., (1964) Choice of Adjustments to Floods, Research Paper No.93, Department of Geography, University of Chicago, Chicago

White G. F., (ed.), (1961) Papers on Flood Problems, Research Paper No.70, Department of Geography, University of Chicago, Chicago

Wisner B., Blaikie P., Cannon T. and Davis I., (2004) At Risk: Natural Hazards, People’s Vulnerability, and Disasters, second edition, Routledge, London

World Bank, (2004) 'Natural Disasters: Counting the Cost'. World Bank press release March 2nd, Online. Available: HTTP: http://go.worldbank.org/NQ6J5P2D10 (accessed 1 September 2007)

\section{Endnotes}

\footnotetext{
${ }^{1}$ Although the focus of this paper is on 'construction practice', the authors recognise that there are many economic, cultural, social structural and discursive factors that can constrain resilient practices but which cannot be covered within the scope of this paper.

${ }^{2}$ The seven guiding principles presented in this paper are based upon a substantial reworking of a chapter written by the authors (see Dainty and Bosher 2008) within a multi-authored edited book (Bosher ed. 2008). The authors therefore acknowledge the important contributions of the many people that contributed towards the edited book; it was through the input of these multi-disciplinary perspectives that the need for the seven guiding principles arose.

${ }^{3}$ The authors are grateful for the comments from the anonymous referees that provided particularly helpful suggestions regarding current and appropriate frameworks and guidance plus a number of pertinent publications.

${ }^{4}$ While not construction focused, the 'Wingspread Principles' (Smart Communities Network n.d.) and 'Shanghai Principles' (Geis 2002) are useful for encouraging thinking on construction-related and 'construction-in-a-widercontext' issues.

${ }^{5}$ The ‘Tools for Mainstreaming Disaster Risk Reduction' can be downloaded from the ProVention Consortium website at URL: http://www.proventionconsortium.org/themes/default/pdfs/tools_for_mainstreaming_DRR.pdf
} 